\title{
O PROJETO EDUCATIVO EMANCIPATÓRIO DE BOAVENTURA DE SOUSA SANTOS E O RESGATE DA MEMÓRIA: MÚLTIPLOS OLHARES DE UMA EDUCAÇÃO HUMANÍSTICA A PARTIR DO ENSINO DA DITADURA MILITAR
}

\author{
EL PROYECTO EDUCATIVO DE EMANCIPACIÓN BOAVENTURA DE SOUSA \\ SANTOS Y EL RESCATE DE LA MEMORIA : DIFERENTES PUNTOS DE VISTA \\ DE UNA EDUCACIÓN HUMANISTA DE LA ENSEÑANZA DE LA DICTADURA \\ MILITAR
}

\author{
Lívia Salvador Cani ${ }^{1}$
}

\section{RESUMO}

Esta pesquisa questiona: Em que medida o desenvolvimento do Projeto Educativo Emancipatório de Boaventura de Sousa Santos e o resgate da memória a partir do ensino da Ditadura Militar, pode contribuir para uma educação humanística? Objetiva-se analisar o ensino da Ditadura Militar na rede pública municipal em Vitória-ES; a relevância do projeto educativo emancipatório de Santos e o resgate da memória na educação e a necessidade do desenvolvimento de um currículo pós crítico para a emancipação do aluno.

Palavras Chave: Memória; Currículo; Educação Humanística; Ditadura Militar.

\begin{abstract}
This research questions: To what extent can the development of the Emancipatory Educational Project of Boaventura de Sousa Santos and the rescue of memory from the teaching of the Military Dictatorship contribute to a humanistic education? The objective of this research is to analyze the teaching of the Military Dictatorship in the municipal public schools of Vitória - ES, the relevance of the emancipatory educational project of Santos and the rescue of the memory in education and the necessity of the development of a curriculum post critical for the emancipation of the student.
\end{abstract}

Keywords: Memory; Curriculum; Humanist Education; Military Dictatorship.

\footnotetext{
${ }^{1}$ Doutoranda em Direito e Sociologia pela Universidade Federal Fluminense - UFF, Mestre em Direitos e Garantias Fundamentais pela Faculdade de Direito de Vitória - FDV, professora universitária. Espírito Santo (Brasil). E-mail: liviascani@gmail.com
} 


\section{INTRODUÇÃO}

Não há como sem pensar em uma sociedade sem memória, pois o passado é pilar para a compreensão do presente, bem como fundamental para a construção do futuro, não se repetindo os erros do passado. É necessária a manutenção e o resgate da memória, pois desta forma proporciona-se o não esquecimento, já que este pode ocasionar a estagnação política e até mesmo social.

A memória é de grande relevância para a formação do indivíduo e fundamental para o desenvolvimento crítico, a partir de sua ressignificação, e a educação é um mecanismo de sua disseminação e fortalecimento.

A preocupação em manter viva a história de uma sociedade, nos remete à importância para a construção da identidade de um povo, que será construída a partir do resgate e posterior ressignificação dos fatos pretéritos e suas consequências no presente. Conservar a memória situa o individuo no tempo, o conscientiza sobre seus iguais, buscando direitos e exercendo a cidadania.

Inicialmente, será desenvolvida a necessidade de uma educação humanística a partir do resgate da memória da Ditadura Militar no ensino básico brasileiro, e de que maneira este período histórico faz-se relevante para conscientização do papel da democracia na efetivação de direitos fundamentais.

O segundo tópico será desenvolvido a partir da importância do resgate da memória na educação, para a concretização de um Projeto Educativo Emancipatório proposto por Boaventura de Sousa Santos, bem como a sua necessidade para a emancipação do indivíduo em formação crítica.

E por fim, o desenvolvimento de um currículo pós-crítico como ferramenta de emancipação do aluno, utilizando a memória como mecanismo de criticidade para o rompimento de dominação.

Esta pesquisa fundamenta-se a partir do seguinte indagação: Em que medida o desenvolvimento do Projeto Educativo Emancipatório de Boaventura de Sousa Santos e o resgate da memória a partir do ensino da Ditadura Militar ao nono ano do Ensino Fundamental da rede pública do município de Vitória - ES, pode contribuir para uma educação humanística?

Desta feita, objetiva-se analisar o ensino da Ditadura Militar na educação básica; verificar a relevância do projeto educativo emancipatório de Santos e o resgate da memória na 
educação e identificar a necessidade do desenvolvimento de um currículo pós crítico para a emancipação do aluno.

A metodologia utilizada nesta pesquisa será a fenomenológica em que se busca analisar o objeto e os fenômenos que virão a se desenrolar. É possível verificar a relação desta pesquisa com o eixo temático Currículo, haja vista que esta pesquisa propõe um currículo pós crítico que se fundamente na emancipação do individuo, ressignificando as violações dos direitos humanos ocorridos durante o período da Ditadura Militar brasileira. Assim, potencializando a conscientização e a criticidade dos alunos em relação a realidade social na qual estão inseridos.

\section{A EdUCAÇÃo hUMANíStiCA A PARTIR do RESGATE DA MEMÓRIA DA DITADURA MILITAR NO ENSINO BÁSICO}

Olhar para o ensino da Ditadura Militar brasileira, na educação básica, pode representar o cumprimento de conteúdos previstos nos currículos de história. Resgatar esse período histórico de grande violação de direitos, com assassinatos, perseguições, torturas, dentre outros crimes é utilizar-se da educação como ferramenta para a concretização e fortalecimento da democracia.

A partir de diálogos entre professores e alunos, sobre as violações de direitos, é possível trazer para a discussão a importância do resgate da memória deste período, para a compreensão da relevância da alteridade. Cabe ao docente na disseminação deste conteúdo buscar a conscientização destes indivíduos sobre o respeito ao outro.

Para Freire (1980, p. 40), “o homem não pode participar ativamente na história, na sociedade, na transformação da realidade, se não é auxiliado a tomar consciência da realidade e de sua própria capacidade de transformá-la". É partir desta consciência dos resquícios do passado, na sociedade atual, o aluno compreenderá seu papel como sujeito na transformação e na construção da história.

Diante da importância de conteúdos que narram períodos de autoritarismo com a violação de direitos, como a Ditadura Militar brasileira, os professores se deparam com a discussão de temas considerados sensíveis, que relatam um passado problemático, que muitos não querem lembrar. Para Araújo (2013) este período, remete a temas sensíveis não apenas 
porque é difícil falar sobre eles, mas pelo fato de não haver ainda, na maioria dos casos, um consenso da sociedade sobre o que dizer e como falar sobre o passado.

O professor, nesta perspectiva, é uma importante ferramenta, não somente para promover o conhecimento, como também a criticidade do aluno na concepção da prejudicialidade da violação de direitos e no fortalecimento da democracia. A transferência destes valores não é uma tarefa simples, já que em muitos locais à violação dos direitos, que ocorreram durante o período militar, ainda persistem.

A educação e em específico, a disciplina de história no Ensino Fundamental é sem dúvida, um pilar para a construção de princípios éticos e da alteridade no indivíduo em formação. Sobre esta pedagogia de libertação do indivíduo Freire diz:

\footnotetext{
Uma educação que possibilite ao homem a discussão corajosa de sua problemática. De sua inserção nesta problemática. Que o advertisse dos perigos de seu tempo, para que, consciente deles, ganhasse a força e a coragem de lutar, ao invés de ser levado e arrastado à perdição de seu próprio "eu", submetido às prescrições alheias. Educação que o colocasse em dialogo constante com o outro. (1978, p. 90)
}

Cumpre aos educadores romper com os silêncios, com a cultura do esquecimento e do medo tão presentes no Brasil, trazendo para os alunos as verdades e as vozes que foram caladas por anos. Sem o conhecimento das barbáries ocorridas, dos erros cometidos estaremos sempre suscetíveis às reincidências de governos autoritários.

Assim, é necessário o uso da educação e do professor como interlocutor de uma pedagogia que liberte, emancipe o sujeito das dominações, das alienações. Só é possível a compreensão de uma educação que fizesse do homem um ser cada vez mais consciente de seus direitos, que deve ser usada criticamente, ou com acento cada vez maior de racionalidade (FREIRE, 1978).

A sala de aula deve ser o local de trazer memórias silenciadas à tona, mostrando aos alunos a importância destes resgates para conscientização do cidadão das dominações e ideologias impostas. O professor de história deve favorecer o aluno, um sujeito inserido na história, e capaz de transformar a realidade na qual está inserido.

A partir de um projeto educativo emancipatório, a ser colocado em prática no ensino da Ditadura Militar brasileira, é possível verificar a teoria da Sociologia das Ausências de Boaventura de Sousa Santos, com o inconformismo diante do desperdício das experiências. 
Diante deste inconformismo constante presente na Sociologia das Ausências e a expansão do presente, que são as ausências, os educadores podem desenvolver com seus alunos a revolta e o inconformismo das diversas violações de direitos ocorridas durante a Ditadura Militar. Rabelo e Francischetto (2008) acreditam que o sentimento de inconformismo é fundamental para o desenvolvimento de um projeto educativo que se pretende emancipatório.

Com efeito, os conteúdos referentes ao período da Ditadura Militar brasileira não devem ser transmitidos como mais uma triste passagem da história do país, mas como um período recente, que não se deve repetir.

\section{O PROJETO EDUCATIVO EMANCIPATÓRIO DE BOAVENTURA DE SOUSA SANTOS E O RESGATE DA MEMÓRIA NA EDUCAÇÃO}

A memória mostra-se de grande relevância na construção da identidade do indivíduo a partir de seu resgate e posterior ressignificação. Ela possibilita a compreensão da realidade social na qual o sujeito está inserido, sendo a rememoração, um mecanismo para não esquecer o passado, evitando que os mesmos erros sejam cometidos.

$\mathrm{Na}$ educação básica, onde se desenvolve a formação dos futuros cidadãos, o resgate e a ressignificação da memória é relevante para a emancipação crítica destes indivíduos, propondo-se assim, o desenvolvimento do Projeto Educativo Emancipatório de Boaventura de Sousa Santos.

Busca-se com a construção deste projeto, a emancipação do estudante, a partir da efetivação do resgate da memória nas instituições escolares. Assim, professores e alunos, seriam ferramentas de concretização do Direito Fundamental à Memória, trazendo à tona fatos históricos silenciados e versões equivocadas, dando um novo sentido a história do Brasil.

Este projeto educativo emancipatório, viria a romper com o silenciamento de vozes e fatos ocultos recorrentes do período da Ditadura Militar brasileira, trazendo para o ambiente escolar, pessoas que vivenciaram a época, e utilizando também o que propõe Santos (1996), de imagens desestabilizadoras. Este mesmo autor (1996) acredita que se devem buscar experiências progressistas no passado, não sendo uma tarefa simples. 
O que se verifica é uma significativa violência, institucionalizada e banalizada pela sociedade, podendo ser consequência da falta do resgate da memória, por possuir o Brasil um povo com pouco acesso à cultura e a educação de qualidade, bem como uma grande exaltação do futuro e uma desconsideração do passado.

Este projeto educativo emancipatório procura gerar o inconformismo dos estudantes diante dos erros cometidos no período ditatorial, rememorando experiências desperdiçadas. Sendo assim, verifica-se, dentro deste projeto a utilização da Sociologia das Ausências, também criada por Santos, em que:

[...] visa, assim, criar uma carência e transformar a falta da experiência social em desperdício da experiência social. Com isso cria as condições para ampliar o campo das experiências credíveis neste mundo e neste tempo e, por essa razão, contribui para ampliar o mundo e dilatar o presente. A ampliação do mundo ocorre não só porque aumenta o campo das experiências credíveis existentes, como também porque, com elas, aumentam as possibilidades de experimentação social no futuro (2010, p. 105).

Esta ampliação das experiências sociais para uma melhor compreensão do presente, com a sua expansão e um mecanismo de fazer com que o indivíduo em formação entenda as consequências do passado na atualidade e a perpetuação de erros. Isso mostra ser cada vez mais necessário o resgate da memória do período da Ditadura Militar, fazendo com que o estudante compreenda as causas da grande violência existente na sociedade.

O Ministério da Educação e Cultura - MEC, através da edição dos Parâmetros Curriculares Nacionais do Ensino Médio, já reconheceu a importância da efetivação do Direito Fundamental à Memória. Este direito faz parte da cidadania cultural brasileira, sendo necessário a sua proteção, por constituir parte do Patrimônio Cultural, porém, estabelece que parte da memória será preservada e lembrada e que outra, será silenciada e esquecida (BRASIL).

O ponto central, sem dúvida é: por que esquecer? Ou mesmo, o que deve ser esquecido? É possível visualiza na educação brasileira o esquecimento de fatos históricos de grande relevância para a formação crítica e social do cidadão, destacando a inserção obrigatória no currículo oficial da rede de ensino da temática História e Cultura AfroBrasileira e Indígena, por meio da Lei 11.645 de 10 de março de 2008 (BRASIL). Deve-se procurar educar o aluno, consciente de ideologias e dominações por parte de governos autoritários, como ocorreu na Ditadura Militar brasileira, que perdurou por vinte e um anos. 
Em relação a esta formação crítica e social do indivíduo, Rabelo e Francischetto são enfáticas ao afirmar que:

Dentro desta proposta pedagógica libertadora, toda ação educativa precisa ser precedida de uma reflexão acerca do próprio homem e de seu meio de vida, sob a pena de se adotar diretrizes de trabalho que o reduzam a mero objeto e não sujeito do ato educativo. Os homens são vistos como seres históricos e, portanto, inacabados (2008, p. 85).

Conteúdos como o período do governo militar brasileiro, são de grande valia para uma reflexão das violações de direitos e a sua perpetuação. Considerar o sujeito, como ser histórico e agente transformador da sociedade é de suma importância, para compreender que o desrespeito de direitos básico na atualidade que também advém deste período histórico.

A partir de uma aprendizagem de conhecimentos conflituantes com o objetivo de por meio dele, produzir imagens radicais e desestabilizadoras dos conflitos sociais em que traduziram o passado, imagens capazes de indignar e rebelar o indivíduo, Santos (1996) acredita para a efetivação do Projeto Educativo Emancipatório.

É preciso transformar a escola em um espaço de diálogo, desenvolvendo no ambiente escolar, um novo campo de possibilidades. Trazer para as escolas os perseguidos políticos da época para que relatem aos jovens suas experiências é um mecanismo, não somente de resgate da memória, mas de conscientização da realidade da época.

Essas vozes silenciadas, trazidas para dentro da arena escolar, são o que Santos (1996) denomina de projeto de memória e denúncia e ainda, um projeto de comunicação e cumplicidade. Somente a fala dos docentes, narrando em terceira pessoa e os textos didáticos, podem não atingir o inconformismo. Já uma narrativa daqueles que sofreram com o Estado ditatorial, poderia ser um gatilho gerador de indignação ${ }^{2}$.

Outro ponto a ser destacado, ao que se propõe um Projeto Educativo Emancipatório no resgate da memória e seu posterior fortalecimento, é uma revisão curricular ao que se trata sobre os conteúdos da Ditadura Militar desenvolvido nas escolas.

Para Santos (1996) aos conteúdos curriculares é possível dar sentidos inesgotáveis, por meio de emoções, sentimentos e paixões, podendo assim produzir imagens radicais que

\footnotetext{
${ }^{2}$ É possível o desenvolvimento desta proposta nas unidades escolares pesquisada, haja vista, a existência de um número expressivo de ex-perseguidos políticos no Espírito Santo, conforme demonstra a pesquisa de Bruno Ribeiro Machado: "A efetivação do Direito Fundamental à Memória como etapa da Justiça de Transição no Brasil: uma visão a partir dos relatos dos perseguidos políticos que atuaram no Espírito Santo", em que foram entrevistados dez indivíduos que sofreram perseguições pelo governo militar.
} 
alimentem o inconformismo, perante o presente que se repete, repetindo as opções indesculpáveis do passado.

O resgate da memória é essencial para a formação crítica do indivíduo, conscientizando o estudante a partir das experiências passadas as suas consequências na atualidade e na sua realidade social. O que se busca com esta prática é gerar o inconformismo e a indignação no aluno, o que não ocorre em alguns casos relatados pelos entrevistados.

A teoria de Santos (1996) nos traz que o passado, muitas vezes desconsiderado e considerado irrelevante, a partir desta realidade, acaba trivializando, banalizando os conflitos e o sofrimento humano de que é feita a repetição da atualidade. O projeto educativo emancipatório, viria juntamente com a efetivação do Direito Fundamental à Memória, desenvolver um senso crítico libertador do educando.

Sobre a educação como ferramenta de libertação do indivíduo, Freire propõe:

Uma educação que possibilite ao homem a discussão corajosa de sua problemática. De sua inserção nesta problemática. Que o advertisse dos perigos de seu tempo, para que, consciente deles, ganhasse a força e a coragem de lutar, ao invés de ser levado e arrastado à perdição de seu próprio "eu”, submetido às prescrições alheias. Educação que o colocasse em diálogo constante com o outro.

O que se almeja, é o protagonismo do aluno como agente transformador da sociedade, juntamente com a escola. E a partir da conscientização e compreensão de sua realidade social se encoraje para modificar e construir, dando fim ao conformismo.

Para a concretização deste projeto educacional, através do resgate da memória, busca por meio do desperdício das experiências, ressignificar o entendimento da história do Brasil aos estudantes da educação básica. Este projeto pedagógico de Santos (1996) pautado no inconformismo e na indignação, transformando assim, a sala de aula em um campo de conhecimento, em que alunos e professores devem optar as possibilidades.

Santos é enfático ao afirmar:

A conflitualidade do passado, enquanto campo de possibilidades e decisões humanas é assumida no projeto educativo como conflitualidade de conhecimentos. Para este projeto educativo não há uma, mas muitas formas ou tipos de conhecimento (1996, p. 17).

Estas experiências desperdiçadas, trazidas pelo resgate da memória, terá por consequência o surgimento de uma pedagogia das ausências, em que educandos e educadores irão se utilizar da imaginação de experiências passadas e presentes se outras escolhas fossem 
tomadas, somente esta imaginação das consequências do que não ocorreu poderá causar o espanto e a indignação diante das consequências existentes (SANTOS, 1996).

Santos, ainda vai além, propondo:

Educação, pois, para o inconformismo, para um tipo de subjetividade que submete a uma hermenêutica de suspeita a repetição do presente, que recusa a trivialização do sofrimento e da opressão e veja neles o resultado de indesculpáveis opções (1996, p. 17-18).

Gerar o inconformismo e a rebeldia do indivíduo através de imagens desestabilizadoras é um mecanismo de conscientizar o aluno, reinventando a teoria crítica através do desenvolvimento de uma pedagogia do conflito. Esta pedagogia irá olhar para o passado e a partir dele e das escolhas feitas, serão conhecidos e avaliados das consequências das opções realizadas e das que podiam ter sido e não foram realizadas (SANTOS, 1996).

Aplicando a Sociologia das Ausências de Boaventura e seu Projeto Educativo Emancipatório, será possível "libertar as práticas sociais do seu estatuto de resíduo, restituindo-lhes a sua temporalidade própria e, assim, a possibilidade de desenvolvimento autônomo" (SANTOS, 2006, p. 791).

A escola pública, deve ser um local de esperança, em que os alunos, juntamente com os professores, por meio do resgate da memória, sejam capazes de desenvolver um senso crítico, indo além da mera disseminação de conteúdos. A educando, não deve receber os conteúdos, como em depósitos em vasilhas, decorando-os e depois esquecendo. A memória referente ao conteúdo, da Ditadura Militar, deve ser resgatadas em sala de aula, buscando o professor a ressignificação em seus alunos.

Sob a teoria de Freire (2013, p. 81) "educador e educandos se arquivam na medida em que, nesta distorcida visão da educação, não há criticidade, não há transformação, não há saber”. Somente desta forma se alcançará a emancipação do indivíduo, buscando por meio do ensino da história, a compreensão do aluno das consequências do passado no presente e de seu papel de agente transformador da sociedade.

Freire (1980), ainda acredita que conscientizar não significa, ideologizar ou propor palavras de ordem, assim abrindo caminho à expressão das insatisfações sociais, porque estas são componentes reais de uma situação de opressão.

O que se almeja com este Projeto Educativo Emancipatório, é fazer do ambiente escolar não somente um local de transmissão do conhecimento, mas um local de construção 
de ciência e de uma nova realidade social, em que indivíduo emancipados de dominações e opressões lutem por uma sociedade mais justa.

\title{
4 O DESENVOLVIMENTO DE UM CURRÍCULO PÓS CRÍTICO COMO MECANISMO DE EMANCIPAÇÃO DO ALUNO
}

Dentre os mais diversos meios de resgate da memória, e educação é uma importante ferramenta para a concretização deste direito fundamental. A partir da rememoração de fatos e figuras de destaque que são invisibilizadas ${ }^{3}$, o sistema educacional é um meio de ressignificação ${ }^{4}$.

A Lei de Diretrizes e Bases da Educação, que regulamenta o ensino em todos os seus níveis no Brasil, institui sobre a necessidade do resgate a memória brasileira na educação básica, conforme prevê em seu art. 26, §4: "O ensino da História do Brasil levará em conta as contribuições das diferentes culturas e etnias para a formação do povo brasileiro, especialmente das matrizes indígena, africana e europeia" (BRASIL).

Os currículos escolares são mecanismos de resgate da memória, principalmente das memórias silenciadas, que não se restringem aos conteúdos sobre a história e cultura afro e indígena, existindo diversos outros fatos que os currículos não abarcam. Silva,T. (2013, p. 14) acredita que "a questão central que serve de pano de fundo para qualquer teoria do currículo é a de saber qual conhecimento deve ser ensinado".

E a partir desta questão nodal é necessário discutir a importância dos currículos no resgate de memórias silenciadas, ou que se encontram do lado de lá da linha abissal, conforme a teoria de Boaventura de Sousa Santos.

\begin{abstract}
As distinções invisíveis são estabelecidas através de linhas radicais que dividem a realidade social em dois universos distintos: o universo "deste lado da linha" e o universo "do outro lado da linha". A divisão é tal que "o outro lado da linha" desaparece enquanto realidade, torna-se inexistente, e é mesmo produzido como inexistente. Inexistência significa não existir sob qualquer forma de ser relevante ou compreensível (SANTOS, 2008, p. 73 ).
\end{abstract}

\footnotetext{
${ }^{3}$ Entende-se por fatos e figuras invisibilizadas, aquelas não são destacadas ou nem mesmo citadas pelo sistema educacional brasileiro.

${ }^{4}$ Entende-se por ressignificação os novos sentidos que se pode atingir ao se dar visibilidade a fatos e figuras ocultas no sistema de ensino brasileiro.
} 
Ancorado nesta perspectiva de Santos é possível verificar, que diversos conteúdos, que estão do lado de lá da linha abissal são essenciais para a o fortalecimento da memória no Ensino Fundamental. Estas memórias tornam-se esquecidas, inexistentes, por não serem julgadas de relevância, devido muitas vezes, ao eurocentrismo existente no ensino brasileiro. O que vem ocorrendo devido a esta desvalorização de conteúdos relativos à história do Brasil, é o enfraquecimento da memória, e até mesmo o seu esquecimento.

Os currículos, ao delimitarem o deve ser ensinado, acabam por excluir diversos pontos fundamentais para a garantia de memórias invisíveis. Desta feita, muitas vezes, com estes silenciamento o indivíduo acaba sendo educado a partir de ideologias de grupos dominantes, e Silva, T. (2013, p. 55) ainda escreve que “o currículo não está simplesmente envolvido com a transmissão de fatos e conhecimentos objetivos, sendo o local onde, ativamente se produzem e se criam significados sociais".

Como já tratado anteriormente, a memória é um direito fundamental devendo ser efetivado, garantindo-se, seu acesso e disseminação as futuras gerações. Para a concretização deste direito humano, faz-se necessárias políticas públicas que promovam ações em prol de se efetivar o direito fundamental à memória.

Diante da importância deste direito para a formação do cidadão brasileiro, o Ministério da Educação e Cultura nos Parâmetros Curriculares Nacionais do Ensino Médio, que assim dispõe:

\footnotetext{
$\mathrm{O}$ direito à memória faz parte da cidadania cultural e revela a necessidade de debates sobre o conceito de preservação das obras humanas. A constituição do Patrimônio Cultural e sua importância para a formação de uma memória social e nacional sem exclusões e discriminações é uma abordagem necessária a ser realizada com os educandos, situando-os nos "lugares de memória" construídos pela sociedade e pelos poderes constituídos, que estabelecem o que deve ser preservado e relembrado e o que deve ser silenciado e "esquecido" (BRASIL).
}

Os Parâmetros Curriculares Nacionais do Ensino Médio são contraditórios, ao garantirem sobre a importância do Patrimônio Cultural para a formação da memória social e nacional, sem exclusões e discriminações, no entanto, prevê que a memória também será silenciada e esquecida.

Como se observa ao mesmo tempo em que, se almeja proteger e resgatar a memória social e nacional através da educação, verifica-se, a necessidade de se preservar e relembrar, como ainda, silenciar e esquecer. $\mathrm{O}$ esquecimento e o silenciamento ter por consequências a 
invisibilidade de fatos ou de culturas na sociedade, fazendo com que grupos não tenham sua identidade reconhecida.

O fortalecimento da memória no Ensino Fundamental e sua posterior ressignificação pelos estudantes para práticas emancipatórias, fundamentadas na solidariedade e na possibilidade de visibilidade aos silenciados.

É de relevância destacar que o resgate e a ressignificação da memória, traz ao indivíduo um olhar crítico da realidade na qual está inserido, libertando daquele que o domina.

Olhar para o ensino da Ditadura Militar brasileira, na educação básica, pode representar o cumprimento de conteúdos previstos nos currículos de história. Resgatar esse período histórico de grande violação de direitos, com assassinatos, perseguições, torturas, dentre outros crimes é utilizar-se da educação como ferramenta para a concretização e fortalecimento da democracia.

A partir de diálogos entre professores e alunos, sobre as violações de direitos, é possível trazer para a discussão a importância do resgate da memória deste período, para a compreensão dos alunos da relevância da alteridade. Cabe ao docente na disseminação deste conteúdo buscar a conscientização destes indivíduos sobre o respeito ao outro.

Para Freire (1980, p. 40), “o homem não pode participar ativamente na história, na sociedade, na transformação da realidade, se não é auxiliado a tomar consciência da realidade e de sua própria capacidade de transformá-la". É partir desta consciência dos resquícios do passado, na sociedade atual, o aluno compreenderá seu papel como sujeito na transformação e na construção da história.

Diante da importância de conteúdos que narram períodos de autoritarismo com a violação de direitos, como a Ditadura Militar brasileira, os professores se deparam com a discussão de temas considerados sensíveis, que relatam um passado problemático, que muitos não querem lembrar. Para Araújo (2013) este período, remete a temas sensíveis não apenas porque é difícil falar sobre eles, mas pelo fato de não haver ainda, na maioria dos casos, um consenso da sociedade sobre o que dizer e como falar sobre o passado.

O professor, nesta perspectiva, é uma importante ferramenta, não somente para promover o conhecimento, como também a criticidade do aluno na concepção da prejudicialidade da violação de direitos e no fortalecimento da democracia. A transferência 
destes valores não é uma tarefa simples, já que em muitos locais à violação dos direitos, que ocorreram durante o período militar, ainda persistem.

A educação e em específico, a disciplina de história no Ensino Fundamental é sem dúvida, um pilar para a construção de princípios éticos e da alteridade no indivíduo em formação. Sobre esta pedagogia de libertação do indivíduo Freire diz:

\footnotetext{
Uma educação que possibilite ao homem a discussão corajosa de sua problemática. De sua inserção nesta problemática. Que o advertisse dos perigos de seu tempo, para que, consciente deles, ganhasse a força e a coragem de lutar, ao invés de ser levado e arrastado à perdição de seu próprio "eu", submetido às prescrições alheias. Educação que o colocasse em dialogo constante com o outro. (1978, p. 90)
}

Cumpre aos educadores romper com os silêncios, com a cultura do esquecimento e do medo tão presentes no Brasil, trazendo para os alunos as verdades e as vozes que foram caladas por anos. Sem o conhecimento das barbáries ocorridas, dos erros cometidos estaremos sempre suscetíveis às reincidências de governos autoritários.

Assim, é necessário o uso da educação e do professor como interlocutor de uma pedagogia que liberte, emancipe o sujeito das dominações, das alienações. Só é possível a compreensão de uma educação que fizesse do homem um ser cada vez mais consciente de seus direitos, que deve ser usada criticamente, ou com acento cada vez maior de racionalidade (FREIRE, 1978).

A sala de aula deve ser o local de trazer memórias silenciadas à tona, mostrando aos alunos a importância destes resgates para conscientização do cidadão das dominações e ideologias impostas. O professor de história deve favorecer o aluno, um sujeito inserido na história, e capaz de transformar a realidade na qual está inserido.

A partir de um projeto educativo emancipatório, a ser colocado em prática no ensino da Ditadura Militar brasileira, é possível verificar a teoria da Sociologia das Ausências de Boaventura de Sousa Santos, com o inconformismo diante do desperdício das experiências.

Diante deste inconformismo constante presente na Sociologia das Ausências e a expansão do presente, que são as ausências, os educadores podem desenvolver com seus alunos a revolta e o inconformismo das diversas violações de direitos ocorridas durante a Ditadura Militar. Rabelo e Francischetto (2008) acreditam que o sentimento de inconformismo é fundamental para o desenvolvimento de um projeto educativo que se pretende emancipatório. 
Com efeito, os conteúdos referentes ao período da Ditadura Militar brasileira não devem ser transmitidos como mais uma triste passagem da história do país, mas como um período recente, que não se deve repetir.

\section{CONCLUSÃO}

Procurando garantir a preservação e o resgate da memória, nas suas mais diversas formas, esta pesquisa buscou através da educação formal, uma maneira de ressignificar este direito garantido a todos os brasileiros. Sendo a educação obrigatória, até o Ensino Fundamental, e assegurado a todos, verifica-se o seu destaque para a concretização e fortalecimento da memória.

A educação é fundamental para o resgate da memória, conscientizando o sujeito em formação, a Lei de Diretrizes e Bases da Educação - LDB, que regulamenta o ensino brasileiro, reconhece esta necessidade. Essa legislação instituiu em seu texto, o resgate da memória para a compreensão do estudante sobre a formação da sociedade brasileira.

Outro relevante documento que disciplina a educação brasileira, os Parâmetros Curriculares Nacionais - PCN, preveem a importância do Patrimônio Cultural para a formação e conservação da memória social, porém é contraditório ao fatos da história deverão ser esquecidos. Isso, acabar por gerar questionamento sobre o que deve ser ensino e por quê, demonstrando o que Santos diz em sua Teoria da Linha Abissal, o que está do lado de lá, ou seja, o que é invisível, ou desconsiderado.

Diante da importância do resgate da memória para a formação crítica do estudante do ensino básico, esta pesquisa se limitou ao conteúdo da Ditadura Militar brasileira, que ocorreu de 1964 à 1985. Buscou-se a partir deste marcante período histórico ressignificar a memória e compreender as suas consequências na atualidade.

Este governo ditatorial, que perdurou por vinte e um anos, iniciou-se com a tomada do poder pelos militares, que inicialmente alegavam manter a ordem e afastar uma ameaça comunista.

Procurou-se analisar a abordagem do conteúdo referente à Ditadura Militar brasileira, destacando pontos considerados relevantes e os silenciamento de fatos marcantes do período, prejudicando a formação crítica do futuro cidadão. Almejando uma melhor compreensão do 
entendimento deste conteúdo pelos estudantes, a pesquisadora realizou entrevistas com professores da disciplina de história do nono ano do Ensino Fundamental.

Verifica-se que no Brasil, durante o processo de transição da Ditadura Militar para o Estado Democrático de Direito não houve uma ruptura ou um marco, do ponto de vista da redemocratização. Para que ocorra uma construção fortalecida da democracia, são necessárias as abordagens históricas para esta concretização, seja da história sombria ou mesmo de realizações em relação aos Direitos Humanos.

Através da efetivação de um Projeto Educativo Emancipatório, como proposto nesta pesquisa, será possível por meio de imagens desestabilizadoras que causem espanto no estudante, ressignificar a memória deste período histórico. A história possui um papel de grande relevância para a conscientização do indivíduo, pois a partir dela é possível dar um novo significado a violência e a realidade social em que estes estudantes estão inseridos. Esta significação, por não ocorrer, banaliza a violência.

Conclui-se ainda que a violência banalizada é um sintoma que comprova uma discussão social insuficiente e também a falta de conhecimento em diferenciar a tortura ocorrida durante a ditadura, daquela ocorrida na atualidade, coisas distintas.

\section{REFERENCIAS}

ARAÚJO, Maria Paula; SILVA, Izabel Pimentel da; SANTOS, Desirre dos Reis. Ditadura Militar e democracia no Brasil: história, imagem e testemunho. Rio de Janeiro: Ponteio, 2013.

BRASIL. Lei de Diretrizes e Bases da Educação brasileira. Disponível em: <http://portal.mec.gov.br/arquivos/pdf/ldb.pdf> Acesso em 24 set. de 2014.

Lei 11.645 de 11 de março de 2008. Poder Legislativo. Disponível em: <http://www.planalto.gov.br/ccivil_03/_ato2007-2010/2008/lei/111645.htm>. Acesso em 20 jan. 2015.

Parâmetros Curriculares Nacionais: história. Brasília: MEC/SEF, 1998. 
FRANCHISCHETTO, Gilsilene Passon Picoretti e MACHADO, Thiago Luiz D'Agostin. Direito Fundamental à Memória e as comunidades quilombolas no Brasil: a educação como medida de desinvisibilização. Disponível em: < http://www.criticadodireito.com.br/todas-as-edicoes/numero-3-volume-4/direito-fundamentala-memoria-e-as-comunidades-quilombolas-no-brasil-a-educacao-como-medida-dedesinvisibilizacao> Acesso em 01 de dez. de 2013.

FREIRE, Paulo. Conscientização: teoria e prática da libertação: uma introdução ao pensamento de Paulo Freire. São Paulo: Cortez \& Moraes, 1980.

Educação como prática da liberdade. 8. ed. Rio de Janeiro: Paz e Terra, 1978.

Pedagogia do oprimido. 54. ed. Rio de Janeiro: Paz e Terra, 2013.

RABELO, Ana Maria Prestes; FRANCISCHETTO, Gilsilene Passon Picoretti. (Re) Conhecer para dialogar: a universidade popular dos movimentos sociais como um projeto educativo emancipatório. Depoimentos. Vitória, n. 14, p. 79-94, jul.- dez. 2008

SANTOS, Boaventura de Sousa. A gramática do tempo: para uma nova cultura política. 3. ed. São Paulo: Cortez, 2010.

Para além do pensamento abissal: das linhas globais a uma ecologia dos saberes. In: PEREIRA, Flávio Henrique Unes; DIAS , Maria Tereza Fonseca (Org.). Cidadania e Inclusão Social: estudos em homenagem à professora Miracy Barbosa de Sousa Gustin. Belo Horizonte: Fórum, 2008, p. 73-102.

SANTOS, Boaventura de Sousa. Para uma pedagogia do conflito. In: SILVA, Luiz Heron Da; AZEVEDO, José Clóvis de; SANTOS, Edmilson Santos dos. (Orgs.) Novos mapas culturais, novas perspectivas educacionais. Sulina: Porto Alegre, 1996.

Para uma sociologia das ausências e uma sociologia das emergências. In:

(Org.). Conhecimento Prudente para uma Vida Decente. 2. ed. São Paulo: Cortez, 2006.

SILVA, Tomáz Tadeu da. Documentos de Identidade: uma introdução às teorias do currículo. 3. ed. Belo Horizonte: Autêntica, 2013. 